\title{
Comparison of post-implant dosimetrics between intraoperatively built custom-linked seeds and loose seeds by sector analysis at 24 hours and 1 month for localized prostate cancer
}

\author{
Eiichiro Okazaki, MD, PhD!, Katsuyuki Kuratsukuri, MD, PhD², Tomohiro Nishikawa, MD³, Tomoaki Tanaka, MD, PhD², \\ Mai Sakagami, MD³, Keiko Shibuya, MD, PhD³ \\ 'Department of Radiation Oncology, Saiseikai Nakatsu Hospital, Osaka, Japan, ${ }^{2}$ Department of Urology, Osaka City University Graduate \\ School of Medicine, Osaka, Japan, ${ }^{3}$ Department of Diagnostic and Interventional Radiology/Radiation Oncology. Osaka City University \\ Graduate School of Medicine, Osaka, Japan
}

\begin{abstract}
Purpose: To compare post-implant dosimetrics between intraoperatively built custom-linked (IBCL) seeds and loose seeds (LS) at 24 hours and 1 month by sector analysis, and to evaluate the effect of IBCL seeds with regard to change in dosimetric parameters, in patients with prostate cancer treated with brachytherapy.

Material and methods: Consecutive patients treated for localized prostate cancer who received definitive brachytherapy between March 2013 and October 2017 were retrospectively analyzed. Prostate $V_{100}\left(P_{100}\right)$, prostate $\mathrm{D}_{90}\left(\mathrm{PD}_{90}\right)$, prostate $\mathrm{V}_{150}\left(\mathrm{PV}_{150}\right)$, urethral $\mathrm{D}_{30}\left(\mathrm{UD}_{30}\right)$, urethral $\mathrm{V}_{150}\left(\mathrm{UV}_{150}\right)$, and rectal $\mathrm{V}_{100}\left(\mathrm{RV}_{100}\right)$ were assessed.

Results: Thirty-two patients were treated with LS and 32 patients were treated with IBCL seeds. The median follow-up time was 49.9 months in the LS group and 27.1 months in the IBCL group. PV $150, \mathrm{UV}_{150}$, and $\mathrm{UD}_{30}$ at 24 hours and $\mathrm{UD}_{30}$ at 1 month showed significant difference (F-test), and standard deviation (SD) tended to be lower in the IBCL group. Analysis of change in the variables revealed significance for $\Delta \mathrm{PV}_{100}$ and $\Delta \mathrm{PD}_{90}(F$-test, $p=0.014$ and $<0.001$, respectively), and $\Delta \mathrm{PV}_{150}$ and $\Delta \mathrm{UD}_{30}$ showed marginal significance ( $p=0.084$ and 0.097 , respectively). $\mathrm{PV}_{150}, \mathrm{UV}_{150}$, and $U_{30}$ at 24 hours and 1 month were significantly lower in the IBCL group, and there was no significant difference in $\mathrm{PV}_{100}, \mathrm{PD}_{90}$, and $\mathrm{RV}_{100}$ compared with the LS group ( $t$-test). The homogeneity index $(\mathrm{HI})$ was significantly higher in the IBCL group $(p<0.001)$.

Conclusions: In this retrospective single institutional study, there was a decrease in the SD of the dosimetric parameters in the IBCL group, and it was statistically significant in change in the variables between 24 hours and 1 month (F-test). The use of IBCL seeds significantly decreased $\mathrm{PV}_{150}, \mathrm{UV}_{150}$, and $\mathrm{UD}_{30}$, and significantly improved $\mathrm{HI}$, without lowering $\mathrm{PD}_{90}$ or $\mathrm{PD}_{100}$.
\end{abstract}

J Contemp Brachytherapy 2020; 12, 4: 317-326 DOI: https://doi.org/10.5114/jcb.2020.98110

Key words: brachytherapy, low-dose-rate, prostate cancer, IBCL seed, loose seed.

\section{Purpose}

Prostate cancer is one of the most common malignancies in men and is a major cause of cancer death [1]. Prostate-specific antigen (PSA) screening enables the detection of early and localized prostate cancer. There are many therapeutic options for patients with localized prostate cancer, including androgen deprivation therapy (ADT), radical prostatectomy, external beam radiation therapy, and brachytherapy. Permanent seed brachytherapy, also termed low-dose-rate (LDR) brachytherapy, enables a high-dose of radiation to the prostate, with a steep dose gradient to the surrounding normal tissues. Previous reviews have shown that outcomes of brachytherapy for localized prostate cancer are comparable to those of other therapeutic modalities, including radical prostatectomy and external beam radiation therapy $[2,3,4]$.

Zauls et al. first reported intraoperatively built custom-linked (IBCL) seeds, as a push-button delivery system that uses a combination of seeds, connectors, and spacers [5]. LDR brachytherapy was first adopted in 2003 in Japan, but stranded or linked seeds were not introduced until 2012, and only loose seeds (LS) had been 
used for LDR brachytherapy until then [6]. Several studies have reported the advantages and disadvantages of IBCL seeds compared with LS [5,7,8,9,10,11,12,13]. IBCL seeds have the advantages of less migration, and stability due to intraoperative linking, indicating the benefits of loose and stranded seeds [14]. Therefore, we hypothesized that compared with LS, the use of IBCL seeds might reduce variance in the dosimetric parameters. To the best of our knowledge, no previous report has evaluated the variability in dosimetric parameters in a comparison of IBCL seeds and LS.

Moreover, the optimal timing for obtaining post-implant computed tomography (CT) and/or magnetic resonance (MR) imaging remains a debated issue. Because prostatic edema arises in the first 24 hours after implantation, post-implant imaging obtained within 24 hours results in lower calculated doses $[15,16]$. Some studies suggest an interval of 2 to 6 weeks after implantation, when prostatic edema has decreased [17,18]; whereas others have recommended dosimetric evaluation within 24 hours, because this allows for immediate correction of a possible dose deficiency $[19,20,21]$. In addition, although most previous reports refer to the dosimetric parameters of the whole prostate, some have evaluated dose distribution in different regions of the prostate [10]. We have previously reported the usefulness of sector analysis for localized prostate cancer treated with LS [22].

The purpose of this study was to compare the dose distribution and to evaluate the variation in dosimetric parameters between IBCL seeds and LS, using sector analysis at 24 hours and 1 month after brachytherapy.

\section{Material and methods}

\section{Patient characteristics}

This study was approved by our Institutional Review Board and was conducted in accordance with the principles of the Declaration of Helsinki. Patients treated with brachytherapy alone at our institution were eligible for this study. A total of 64 consecutive patients were retrospectively analyzed, including those treated with LS between March 2013 and August 2015 (LS group, $n=32$ ), and those treated with IBCL seeds between September 2015 and October 2017 (IBCL group, $n=32$ ). Patients were staged according to the American Joint Committee on Cancer guidelines ( $7^{\text {th }}$ edition), and were classified into prognostic risk groups according to the National Comprehensive Cancer Network (NCCN: www.nccn.org) guidelines. Neoadjuvant ADT to reduce prostate volume was generally administered to patients, with volumes $>40 \mathrm{cc}$.

\section{Pre-implant planning}

MRI-based pre-implant volume evaluations were performed, with the patient in the supine position, using a 1.5 T Avanto scanner (Siemens Medical Solutions, Erlangen, Germany) at a median of 8 weeks (range, 2-20 weeks) before implantation. T2-weighted 3D MR images of $2.5 \mathrm{~mm}$ thickness were imported into a treatment planning system (TPS). The dosimetry of pre-implant planning aimed for a prostate $\mathrm{V}_{100}\left(\mathrm{PV}_{100}\right.$, the percentage of the volume receiv- ing $100 \%$ of the prescribed dose) of $>95 \%$, a prostate $D_{90}$ ( $\mathrm{PD}_{90}$, the minimum dose received by $90 \%$ of the volume) of $>110 \%$ and $<130 \%$ of the prescribed dose, a prostate $\mathrm{V}_{150}\left(\mathrm{PV}_{150}\right.$, the percentage of the volume receiving $150 \%$ of the prescribed dose) of $<60 \%$, a urethral $\mathrm{D}_{30}\left(\mathrm{UD}_{30}\right.$, the minimum dose received by $30 \%$ of the volume) of $<150 \%$, and a rectal $V_{100}\left(\mathrm{RV}_{100}\right.$, the volume receiving $100 \%$ of the prescribed dose) of $<0.2 \mathrm{cc}$. Urethral $\mathrm{V}_{150}\left(\mathrm{UV}_{150}\right)$ was also recorded, but not used as a dose constraint.

\section{Implant procedure}

The implant procedure was performed under spinal anesthesia, with the patient in the dorsal lithotomy position. For all patients, iodine- 125 seeds (BARD, BrachySource model, Covington, GA, USA) with an apparent activity of $0.342 \mathrm{mCi}$ and an air kerma strength of $0.432 \mathrm{U}\left(\mu \mathrm{Gym}^{2} / \mathrm{h}\right)$ were used, and the prescribed brachytherapy dose was $145 \mathrm{~Gy}$. The seeds were implanted transperineally with a Mick applicator (Mick Radio-Nuclear Instruments, New York, NY, USA) and under the guidance of real-time transrectal ultrasonography. A modified peripheral loading technique was used to deliver the dose to the prostate, avoiding placement of seeds close to the urethra [23]. Dose-volume constraints for the prostate, urethra, and rectum were the same as in the pre-implant planning. Until March 2014, an Interplant (Computerized Medical Systems, Champaign, IL, USA) TPS was used for pre-implant and real-time planning, and an Oncentra (Nucletron, Veenendaal, The Netherlands) TPS was used from April 2014.

\section{Post-implant dosimetry}

Post-implant axial CT images of the pelvis were obtained 24 hours and 1 month (median, 29 days) after the implant procedure, using an Asteion (Toshiba Medical Systems, Tokyo, Japan) at $2.0 \mathrm{~mm}$ thickness with the patient in the supine position. Post-implant dosimetric analysis was re-planned with the Oncentra TPS by a single radiation oncologist (E.O.). CT-MR image fusion for delineation was performed for all patients with the Oncentra TPS, using the MR images obtained in the pre-implant volume studies. The percentage changes in the volumetric parameters after 24 hours and 1 month were defined as follows:

$$
\begin{gathered}
\Delta \text { variable }(\%)=\left(\text { variable }_{1 \text { month }}-\text { variable }_{24 \mathrm{~h}}\right) / \\
\text { variable }_{24 \mathrm{~h}} \times 100
\end{gathered}
$$

Homogeneity index (HI) was defined as follows [24]:

$$
\mathrm{HI}(\%)=\left(\mathrm{PV}_{100}-\mathrm{PV}_{150}\right) / \mathrm{PV}_{100} \times 100
$$

The prostate volume was divided into four quadrants, such as anterior-superior quadrant (ASQ), posteriorsuperior quadrant (PSQ), anterior-inferior quadrant (AIQ), and posterior-inferior quadrant (PIQ). The superiorinferior and anterior-posterior segments were divided by the midpoint of the prostate on reconstructed CT images (Figure 1) [22].

Seed migration was defined as the presence of one or more seeds $\geq 2 \mathrm{~cm}$ outside the prostate contour on a post-implant pelvic CT or X-ray. Seed loss was defined 

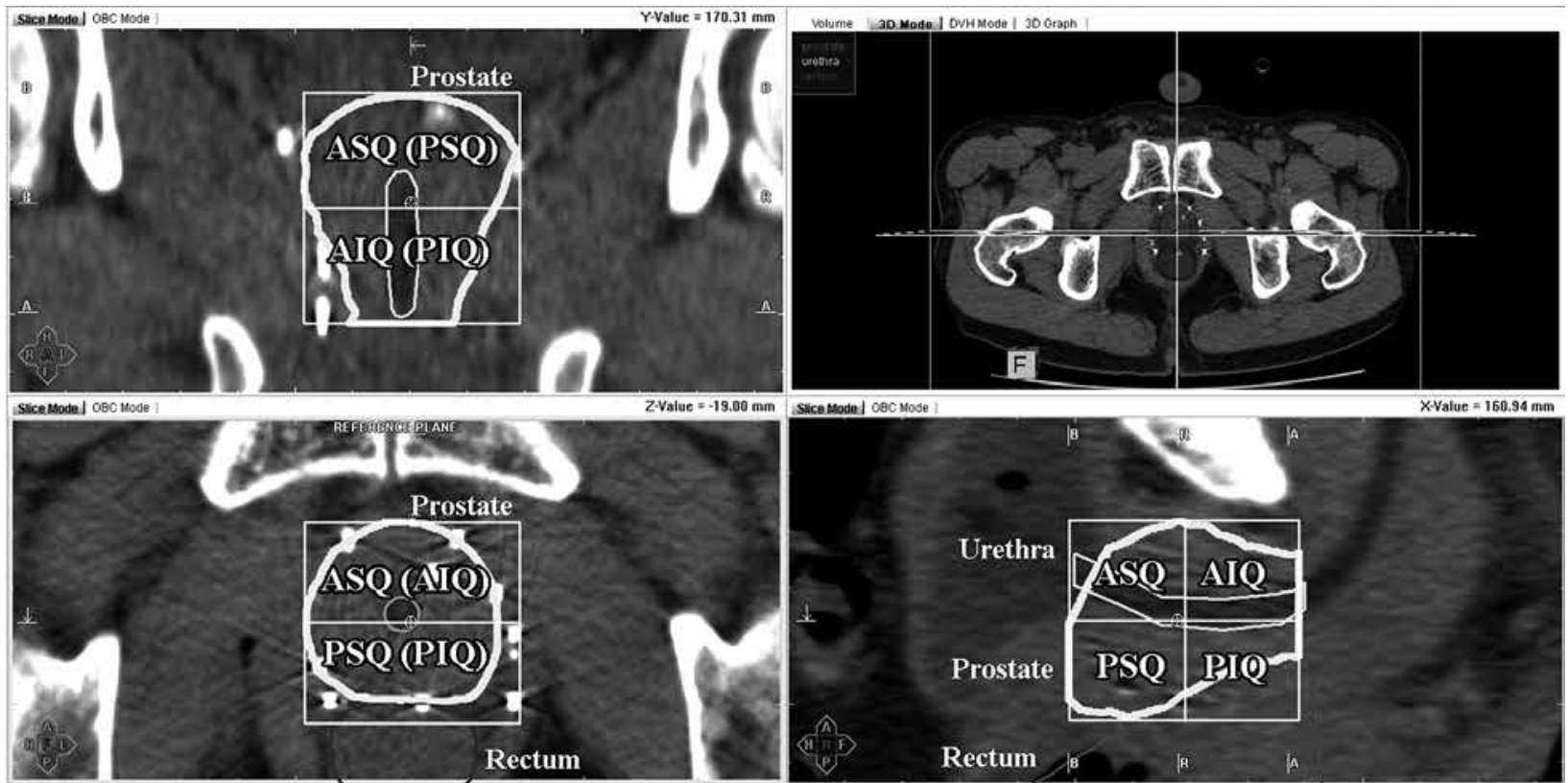

Fig. 1. Division of the prostate into four quadrants

$A S Q$ - anterior-superior quadrant, PSQ - posterior-superior quadrant, AIQ - anterior-inferior quadrant, PIQ - posterior-inferior quadrant

as unintentional reduction of seed number at the postimplant evaluation, excluding migrated seeds.

\section{Patient follow-up}

The date of implantation was considered day 0 in the analysis of follow-up duration. Patients were assessed every 2-3 months during the first to third year, and every 3-6 months at 3-10 years after brachytherapy. Serum PSA levels and adverse events data were collected at the clinical follow-up visits. Biochemical recurrence was determined according to the Phoenix definition [25]. Genitourinary (GU) and gastrointestinal (GI) adverse events were documented using the Common Terminology Criteria for Adverse Events, version 4.0.

\section{Statistical analyses}

An F-test was applied to compare the variance of the two groups, prior to $t$-test. $T$-tests $(p \geq 0.05$ in $F$-test) or Welch's $t$-test $(p<0.05$ in F-test) were used for continuous variables when comparing the baseline characteristics in the two groups, and Fisher exact test was used for categorical variables. One-way analysis of variance (ANOVA) with Tukey's honest significant difference (HSD) was applied for post-hoc testing. Coordinate points of a receiver operating characteristic (ROC) curve were used to identify significant dosimetric parameters for predicting adverse events. Statistical analyses were performed using R environment (version 3.2.2) available from http:/ / www.R-project.org. A $p$ value of $<0.05$ was considered significant.

\section{Results}

Table 1 lists the patient characteristics. The median follow-up time was 49.9 months in the LS group and
27.1 months in the IBCL group $(p<0.001)$. Fourteen patients received neoadjuvant ADT 3-6 months before brachytherapy (luteinizing hormone-releasing hormone agonist, $n=10$; maximum androgen blockade [combination of luteinizing hormone-releasing hormone agonist and anti-androgen], $n=2$; anti-androgen, $n=2$ ). No biochemical recurrence occurred during the follow-up period, and one patient died of lung cancer.

\section{Dosimetric analysis}

Seed migration occurred in 11 patients ( 15 seeds: pelvis, $n=6$; seminal vesicle, $n=5$; lung, $n=4)$ in the LS group and in 3 patients (4 seeds: seminal vesicle, $n=3$; perineum, $n=1)$ in the IBCL group ( $p=0.032)$. Seed loss (excretion via urethra) occurred in 8 patients (14 seeds) in the LS group and none in the IBCL group $(p=0.005)$.

Table 2 presents the post-implant dosimetric data. $P_{150}$ $\mathrm{UV}_{150}$, and $\mathrm{UD}_{30}$ at 24 hours and $\mathrm{UD}_{30}$ at 1 month were significant by F-test, and standard deviation (SD) tended to be lower in the IBCL group than in the LS group (9.2 vs. 13.2, 5.5 vs. 17.6 , and 11.7 vs. 18.5 at 24 hours, and 14.0 vs. 24.3 at 1 month, respectively), and similar trends were seen for most other dosimetric variables except $\mathrm{PV}_{100}$ at 24 hours. Analysis of the variables revealed significant difference for $\triangle \mathrm{PV}_{100}$ and $\Delta \mathrm{PD}_{90}$ by $F$-test, $\Delta \mathrm{PV}_{150}$ and $\Delta \mathrm{UD}_{30}$ showed marginal statistical significance, and the SDs of all variables were lower in the IBCL group. $\mathrm{PV}_{150}, \mathrm{UV}_{150}$, and $\mathrm{UD}_{30}$ at 24 hours and 1 month were significantly lower in the IBCL group compared with the LS group ( $t$-test). There was no significant difference between the two groups in terms of $\mathrm{PV}_{100}, \mathrm{PD}_{90}$, and $\mathrm{RV}_{100}$ at 24 hours and 1 month. $\mathrm{HI}$ at 24 hours and 1 month was significantly higher in the IBCL group compared with the LS group (both $p<0.001$ ).

Table 3 shows the results of dosimetric analysis for each quadrant of the prostate. In the analysis of change 
Table 1. Patient characteristics $(n=64)$

\begin{tabular}{|c|c|c|c|c|}
\hline Variable & All & LS & $\mathrm{IBCL}$ & $p$-value \\
\hline Age (years) & & & & 0.39 \\
\hline Median & 67 & 66.5 & 68.5 & \\
\hline Range & $50-80$ & $53-79$ & $50-80$ & \\
\hline Pre-treatment PSA (ng/ml) & & & & 0.032 \\
\hline Median & 6.2 & 5.6 & 7.4 & \\
\hline Range & $3.3-17.0$ & $3.3-14.0$ & $3.7-17.0$ & \\
\hline Gleason score & & & & 0.31 \\
\hline$\leq 6$ & 39 & 22 & 17 & \\
\hline 7 & 25 & 10 & 15 & \\
\hline Clinical T stage & & & & 0.66 \\
\hline T1c & 29 & 15 & 14 & \\
\hline $\mathrm{T} 2 \mathrm{a}$ & 22 & 12 & 10 & \\
\hline $\mathrm{T} 2 \mathrm{~b}$ & 2 & 0 & 2 & \\
\hline $\mathrm{T} 2 \mathrm{C}$ & 11 & 5 & 6 & \\
\hline NCCN risk group & & & & 0.21 \\
\hline Low & 30 & 18 & 12 & \\
\hline Intermediate & 34 & 14 & 20 & \\
\hline Neoadjuvant ADT & & & & 1.00 \\
\hline No & 50 & 25 & 25 & \\
\hline Yes & 14 & 7 & 7 & \\
\hline Pre-implant prostate volume (ml) & & & & 0.44 \\
\hline Median & 26.0 & 25.5 & 26.9 & \\
\hline Range & 12.0-41.0 & $14.3-37.0$ & $12.0-41.0$ & \\
\hline Number of seeds & & & & 0.93 \\
\hline Median & 66.5 & 66 & 68.5 & \\
\hline Range & $42-89$ & $51-87$ & $42-89$ & \\
\hline Follow-up (months) & & & & $<0.001$ \\
\hline Median & 36.8 & 49.9 & 27.1 & \\
\hline Range & $7.9-67.4$ & $7.9-67.4$ & $12.1-40.4$ & \\
\hline
\end{tabular}

PSA - prostate-specific antigen, NCCN - National Comprehensive Cancer Network, ADT-androgen deprivation therapy, LS - loose seed, IBCL - intraoperatively built custom-linked

in the variables, $\mathrm{SD}$ of $\Delta \mathrm{D}_{90}, \mathrm{PSQ}, \mathrm{AIQ}$, and PIQ was significantly lower in the IBCL group than in the LS group (F-test; $p=0.018,<0.001$, and $<0.001$, respectively). At 24 hours, $\mathrm{D}_{90}$ of PIQ was significantly lower in the LS group than in the IBCL group $(p=0.006)$, and $D_{90}$ of ASQ was significantly higher in the LS group than in the IBCL group $(p=0.037)$. At 1 month, there was no significant difference between the two groups in terms of $\mathrm{D}_{90}$ in any quadrant. In comparison of the quadrants using one-way ANOVA with Tukey's HSD, in the LS group, $\mathrm{D}_{90}$ at 24 hours was significantly lower in PIQ than in the other quadrants, and $D_{90}$ at 1 month was significantly higher in AIQ than in the other quadrants. In the IBCL group, there was no significant difference in $\mathrm{D}_{90}$ at 24 hours among the quadrants, and $\mathrm{D}_{90}$ at 1 month was significantly higher in AIQ than in the other quadrants. $V_{150}$ was significantly or almost significantly lower in the IBCL group compared with the LS group in almost all quadrants, except PIQ at 24 hours.

To analyze the learning curve of LDR brachytherapy, patients from each group were divided into subgroups of 
Table 2. Post-implant dosimetric data for the prostate, urethra, and rectum (24 hours and 1 month)

\begin{tabular}{|c|c|c|c|c|c|c|}
\hline & \multicolumn{2}{|c|}{ LS group } & \multicolumn{2}{|c|}{ IBCL group } & \multirow{2}{*}{$\frac{F \text {-test }}{p \text {-value }}$} & \multirow{2}{*}{$\frac{T \text {-test }^{*}}{p \text {-value }}$} \\
\hline & Mean & SD & Mean & SD & & \\
\hline \multicolumn{7}{|l|}{24 hours } \\
\hline \multicolumn{7}{|l|}{ Prostate } \\
\hline Volume (ml) & 34.7 & 8.0 & 32.0 & 9.0 & 0.52 & 0.22 \\
\hline$V_{100}(\%)$ & 85.2 & 7.3 & 85.6 & 7.5 & 0.89 & 0.66 \\
\hline $\mathrm{V}_{150}(\%)$ & 43.5 & 13.2 & 37.1 & 9.2 & 0.049 & $<0.001$ \\
\hline $\mathrm{D}_{90}(\%)$ & 93.1 & 13.6 & 94.4 & 11.2 & 0.28 & 0.43 \\
\hline $\mathrm{HI}$ & 49.5 & 12.1 & 57.0 & 8.7 & 0.073 & $<0.001$ \\
\hline \multicolumn{7}{|l|}{ Urethra } \\
\hline $\mathrm{V}_{150}(\%)$ & 14.8 & 17.6 & 2.2 & 5.5 & $<0.001$ & $<0.001$ \\
\hline$D_{30}(\%)$ & 132.8 & 18.5 & 117.8 & 11.7 & 0.012 & $<0.001$ \\
\hline \multicolumn{7}{|l|}{ Rectum } \\
\hline $\mathrm{V}_{100}(\mathrm{ml})$ & 0.1 & 0.2 & 0.2 & 0.2 & 0.22 & 0.64 \\
\hline \multicolumn{7}{|l|}{1 month } \\
\hline \multicolumn{7}{|l|}{ Prostate } \\
\hline Volume (ml) & 28.2 & 7.0 & 25.8 & 6.6 & 0.70 & 0.168 \\
\hline $\mathrm{V}_{100}(\%)$ & 91.9 & 5.2 & 93.2 & 4.2 & 0.21 & 0.28 \\
\hline $\mathrm{V}_{150}(\%)$ & 67.5 & 11.7 & 55.8 & 11.1 & 0.75 & $<0.001$ \\
\hline $\mathrm{D}_{90}(\%)$ & 108.1 & 14.8 & 109.4 & 11.9 & 0.24 & 0.69 \\
\hline $\mathrm{HI}$ & 27.0 & 9.7 & 40.4 & 10.4 & 0.72 & $<0.001$ \\
\hline \multicolumn{7}{|l|}{ Urethra } \\
\hline $\mathrm{V}_{150}(\%)$ & 46.5 & 25.0 & 21.3 & 20.9 & 0.32 & $<0.001$ \\
\hline $\mathrm{D}_{30}(\%)$ & 170.1 & 24.3 & 144.7 & 14.0 & 0.003 & $<0.001$ \\
\hline \multicolumn{7}{|l|}{ Rectum } \\
\hline $\mathrm{V}_{100}(\mathrm{ml})$ & 0.5 & 0.5 & 0.4 & 0.4 & 0.097 & 0.22 \\
\hline \multicolumn{7}{|c|}{ Change in variables $(\Delta)$} \\
\hline \multicolumn{7}{|l|}{ Prostate } \\
\hline $\mathrm{V}_{100}(\%)$ & 9.2 & 11.8 & 9.5 & 7.5 & 0.014 & 0.92 \\
\hline $\mathrm{V}_{150}(\%)$ & 41.5 & 32.7 & 53.7 & 23.9 & 0.084 & 0.10 \\
\hline $\mathrm{D}_{90}(\%)$ & 20.3 & 26.4 & 16.4 & 8.4 & $<0.001$ & 0.90 \\
\hline \multicolumn{7}{|l|}{ Urethra } \\
\hline $\mathrm{D}_{30}(\%)$ & 28.6 & 12.7 & 23.2 & 9.4 & 0.097 & 0.062 \\
\hline
\end{tabular}

${ }^{*}$ T-test was performed for variables with $p \geq 0.05$ in F-test, and Welch's $t$-test was performed for variables with $p<0.05, V_{100}-$ the percentage of the volume receiving $100 \%$ of the prescribed dose, $V_{150}$ - the percentage of the volume receiving $150 \%$ of the prescribed dose, $D_{90}$ - the minimum dose received by $90 \%$ of the volume, $\mathrm{D}_{30}$ - the minimum dose received by $30 \%$ of the volume, $\mathrm{HI}$-homogeneity index, $\mathrm{LS}$-loose seed, IBCL-intraoperatively built custom-linked

10, 10, and 12 patients, according to the date of implantation. The learning curve was analyzed using $\mathrm{PD}_{90}, \mathrm{PV}_{100}$, and $P V_{150}$, and no significant difference was observed in terms of the treatment period in each group.

\section{Analysis of adverse events}

No grade 3 or higher GU or GI adverse events were observed. Two patients $(6.3 \%)$ in each group experienced at least one episode of hematuria. Two patients $(6.3 \%)$ in 
Table 3. Post-implant dosimetric data for the four quadrants of the prostate ( 24 hours and 1 month)

\begin{tabular}{|c|c|c|c|c|c|c|}
\hline & \multicolumn{2}{|c|}{ LS group } & \multicolumn{2}{|c|}{ IBCL group } & \multirow{2}{*}{$\frac{F \text {-test }}{p \text {-value }}$} & \multirow{2}{*}{$\frac{T \text {-test }^{\star}}{p \text {-value }}$} \\
\hline & Mean & SD & Mean & SD & & \\
\hline \multicolumn{7}{|l|}{24 hours } \\
\hline \multicolumn{7}{|l|}{ ASQ } \\
\hline$V_{100}(\%)$ & 88.3 & 9.3 & 82.6 & 13.5 & 0.044 & 0.059 \\
\hline $\mathrm{V}_{150}(\%)$ & 56.9 & 19.0 & 35.6 & 13.9 & 0.088 & $<0.001$ \\
\hline $\mathrm{D}_{90}(\%)$ & 106.0 & 24.0 & 94.6 & 17.2 & 0.069 & 0.037 \\
\hline \multicolumn{7}{|l|}{ PSQ } \\
\hline $\mathrm{V}_{100}(\%)$ & 88.7 & 8.2 & 89.0 & 11.0 & 0.104 & 0.89 \\
\hline $\mathrm{V}_{150}(\%)$ & 51.0 & 16.8 & 39.1 & 13.0 & 0.159 & 0.003 \\
\hline $\mathrm{D}_{90}(\%)$ & 102.2 & 15.9 & 102.0 & 13.9 & 0.45 & 0.95 \\
\hline \multicolumn{7}{|l|}{$\mathrm{AlQ}$} \\
\hline$V_{100}(\%)$ & 86.3 & 11.1 & 87.2 & 13.9 & 0.22 & 0.77 \\
\hline $\mathrm{V}_{150}(\%)$ & 55.3 & 20.2 & 40.3 & 15.8 & 0.177 & 0.002 \\
\hline $\mathrm{D}_{90}(\%)$ & 100.8 & 27.8 & 101.5 & 20.4 & 0.089 & 0.91 \\
\hline \multicolumn{7}{|l|}{ PIQ } \\
\hline$V_{100}(\%)$ & 73.1 & 19.1 & 82.8 & 12.8 & 0.028 & 0.023 \\
\hline$V_{150}(\%)$ & 33.7 & 18.4 & 33.9 & 15.0 & 0.25 & 0.96 \\
\hline $\mathrm{D}_{90}(\%)$ & 81.4 & 20.1 & 94.5 & 15.9 & 0.197 & 0.006 \\
\hline \multicolumn{7}{|l|}{1 month } \\
\hline \multicolumn{7}{|l|}{ ASQ } \\
\hline $\mathrm{V}_{100}(\%)$ & 89.3 & 11.7 & 89.4 & 10.4 & 0.49 & 0.97 \\
\hline $\mathrm{V}_{150}(\%)$ & 65.2 & 18.8 & 51.4 & 17.7 & 0.75 & 0.004 \\
\hline $\mathrm{D}_{90}(\%)$ & 111.1 & 26.0 & 105.8 & 19.9 & 0.143 & 0.37 \\
\hline \multicolumn{7}{|l|}{ PSQ } \\
\hline $\mathrm{V}_{100}(\%)$ & 91.6 & 7.9 & 92.9 & 7.2 & 0.59 & 0.50 \\
\hline $\mathrm{V}_{150}(\%)$ & 67.1 & 14.7 & 53.0 & 16.3 & 0.57 & $<0.001$ \\
\hline $\mathrm{D}_{90}(\%)$ & 110.2 & 20.2 & 111.8 & 16.4 & 0.25 & 0.73 \\
\hline \multicolumn{7}{|l|}{$\mathrm{AlQ}$} \\
\hline $\mathrm{V}_{100}(\%)$ & 95.1 & 6.6 & 97.0 & 5.1 & 0.16 & 0.21 \\
\hline $\mathrm{V}_{150}(\%)$ & 74.5 & 16.5 & 66.4 & 20.4 & 0.24 & 0.090 \\
\hline $\mathrm{D}_{90}(\%)$ & 126.8 & 25.0 & 129.1 & 18.3 & 0.089 & 0.69 \\
\hline \multicolumn{7}{|l|}{ PIQ } \\
\hline $\mathrm{V}_{100}(\%)$ & 92.7 & 6.5 & 94.8 & 5.7 & 0.46 & 0.180 \\
\hline $\mathrm{V}_{150}(\%)$ & 64.5 & 18.8 & 55.5 & 17.0 & 0.58 & 0.053 \\
\hline $\mathrm{D}_{90}(\%)$ & 113.3 & 22.8 & 117.3 & 15.7 & 0.043 & 0.43 \\
\hline \multicolumn{7}{|c|}{ Change in variables $(\Delta)$} \\
\hline $\mathrm{D}_{90} \mathrm{ASQ}$ & 5.5 & 14.5 & 12.2 & 11.8 & 0.26 & 0.048 \\
\hline PSQ & 9.5 & 22.4 & 10.4 & 14.5 & 0.018 & 0.48 \\
\hline $\mathrm{AlQ}$ & 34.4 & 48.5 & 30.9 & 26.1 & $<0.001$ & 0.67 \\
\hline PIQ & 45.4 & 40.3 & 25.5 & 14.0 & $<0.001$ & 0.007 \\
\hline
\end{tabular}

${ }^{*}$ T-test was performed for variables with $p \geq 0.05$ in F-test, and Welch's t-test was performed for variables with $p<0.05, A S Q$ - anterior-superior quadrant, $P S Q$ - posterior-superior quadrant, AIO - anterior-inferior quadrant, $P I Q$ - posterior-inferior quadrant, $V_{100}$ - the percentage of the volume receiving $100 \%$ of the prescribed dose, $V_{150}$ - the percentage of the volume receiving $150 \%$ of the prescribed dose, $D_{90}$ - the minimum dose received by $90 \%$ of the volume, LS - loose seed, $I B C L$ - intraoperatively built custom-linked 
the LS group and 1 patient (3.1\%) in the IBCL group experienced rectal hemorrhage. Figure 2 shows the frequency of grade 2 GU adverse events between 3 and 12 months after brachytherapy. At 3 months after treatment, the frequency of GU adverse events was significantly lower in the IBCL group $(p=0.032)$, and there was no significant difference in the other periods. Using $U_{150}$ and $U D_{30}$ at 1 month, ROC analysis was performed for the frequency of GU adverse events after 3 months. The respective cut-off values for $\mathrm{UV}_{150}$ and $\mathrm{UD}_{30}$ at 1 month were $43.5 \%$ $(\mathrm{AUC}=0.70$, sensitivity $=66.7 \%$, specificity $=74.4 \%)$ and $162.1 \%$ (AUC $=0.71$, sensitivity $=66.7 \%$, specificity $=76.7 \%$ ). Figure 3 shows the change in the frequency of grade 2 GU adverse events using the cut-off value of $\mathrm{UV}_{150}$; significant differences at 3,6 , and 9 months $(p<0.001,0.019$, and 0.044 , respectively) were noted.

\section{Discussion}

The results of this study show that compared with LS, the SD of most dosimetric variables was lower for IBCL seeds, and statistically significant differences between the two groups were found for several variables (F-test; $\mathrm{PV}_{150}, \mathrm{UV}_{150}$, and $\mathrm{UD}_{30}$ at 24 hours, and $\mathrm{UD}_{30}$ at 1 month). Although sector analysis of $\mathrm{V}_{150}$ and $\mathrm{D}_{90}$ showed a general decrease in the SD for all sectors in the IBCL group, no statistically significant difference was observed. Analysis of changes in the variables showed a significant or near-significant decrease in SD; in sector analysis, the SD of changes in $\mathrm{D}_{90}$ in the IBCL group was also significantly lower compared with the LS group. These results indicate that compared with LS, the use of IBCL seeds can reduce variance of the dosimetric parameters. More importantly, the reduction in variance due to the use of IBCL seeds was more pronounced in the analysis of changes between 24 hours and 1 month, which indicates that compared with LS, using IBCL seeds improves the accuracy of predicting dosimetric parameters at 1 month, using those obtained at 24 hours. Furthermore, this result may ensure the validity of early dose correction, when dose deficiency is recognized as early as 24 hours after brachytherapy, when IBCL seeds are used.

The use of IBCL seeds also makes it possible to reduce high-dose areas in the prostate, improve $\mathrm{HI}$, and reduce urethral dose for the whole prostate as well as each sector. $\mathrm{PV}_{100}$ and $\mathrm{PD}_{90}$ were not significantly different between the two groups. Many studies have compared dosimetric parameters between these groups, but the results are controversial (Table 4). Several papers have reported no significant difference in $\mathrm{PV}_{100}$ and $\mathrm{PD}_{90}$ between the two groups $[5,8,10]$. Inada et al. reported that $\mathrm{PV}_{100}$ was significantly higher in the IBCL group than in the LS group, whereas other studies showed that $\mathrm{PD}_{90}$ was significantly lower in the IBCL group than in the LS group $[7,11,12,13]$. In several studies, $\mathrm{PV}_{150}$ and $\mathrm{UD}_{30}$ were significantly lower and HI was significantly higher in the IBCL group than in the LS group, consistent with the results of the present study $[7,11]$. Two studies have reported that $R V_{100}$ was significantly lower in the IBCL group than in the LS group, but we found no significant difference in the present study $[7,13]$. We consider that the decrease in varia-

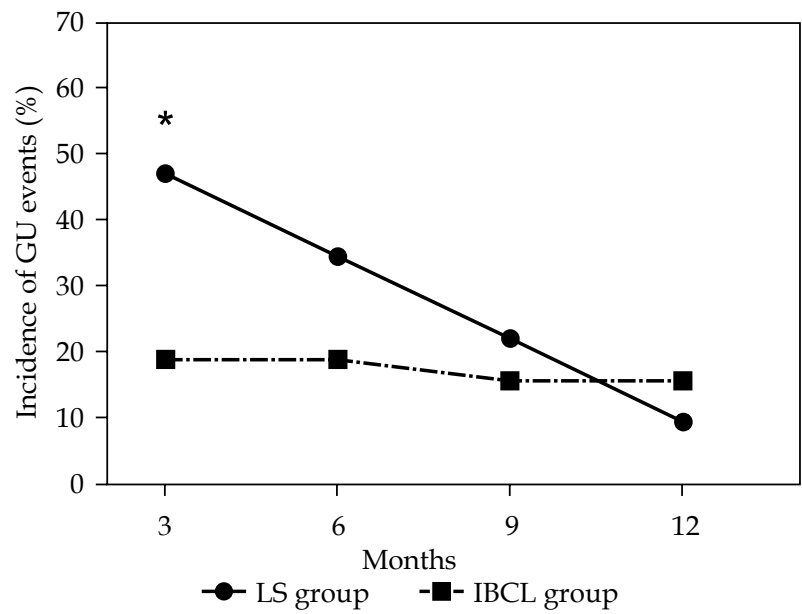

Fig. 2. Incidence of grade 2 or higher GU adverse events between 3 months and 1 year after brachytherapy in the LS and IBCL groups

*Statistically significant difference between the two groups, LS - loose seed, IBCL - intraoperatively built custom-linked, GU - genitourinary

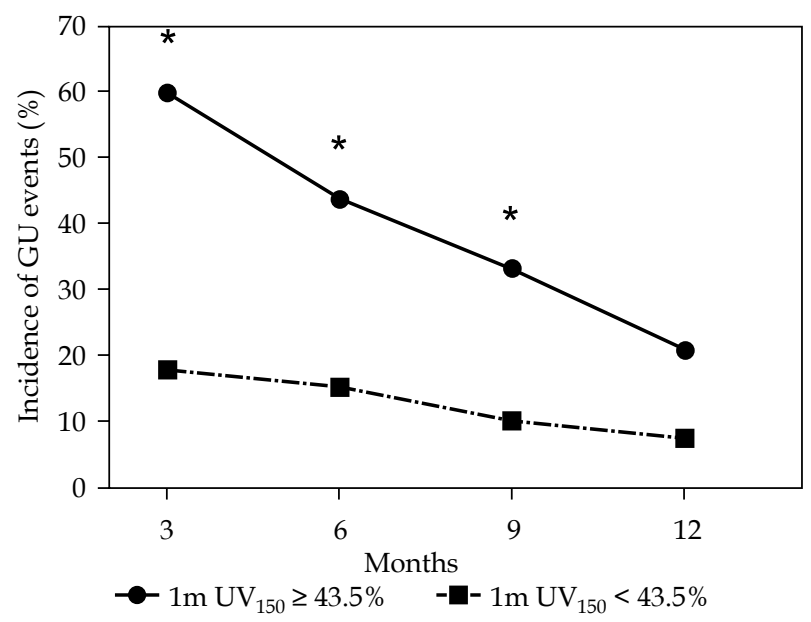

Fig. 3. Incidence of grade 2 or higher GU adverse events between 3 months and 1 year after brachytherapy, based on a cut-off value of $\mathrm{UV}_{150}$

*Statistically significant difference between the two groups, UV 150 - urethral $V_{150}$ (the percentage of the volume receiving $150 \%$ of the prescribed dose), GU-genitourinary

tion of dosimetric parameters and the reduction of highdose areas in both the prostate and urethra are due to the following characteristics of IBCL seeds compared with LS: (i) reduction of seed migration and loss, (ii) suppression of unintentional movement within the prostate after seed implantation, (iii) correct distance between seeds due to use of spacers, and (iv) the ability to intentionally place the seeds outside the prostate, which is particularly useful in peripheral loading techniques, and contributes to reducing urethral dose.

In the sector analysis, although there were no significantly lower sectors in $\mathrm{D}_{90}$ at 24 hours in the IBCL group, $\mathrm{D}_{90}$ of PIQ at 24 hours in the LS group was significantly lower compared with the other sectors. However, there was no significant difference between the two groups 
Table 4. Previously reported data of dosimetric comparisons between LS and IBCL seeds

\begin{tabular}{|c|c|c|c|c|c|c|c|}
\hline Study & Year & $N$ & Dose & Parameters & LS & $\mathrm{IBCL}$ & $p$-value \\
\hline \multirow[t]{4}{*}{ Zauls et al. [5] } & \multirow[t]{4}{*}{2010} & \multirow[t]{4}{*}{91} & 100 Gy (Pd) & $\mathrm{PD}_{90}(\mathrm{~Gy})$ & 98.2 & 104.0 & 0.42 \\
\hline & & & 160 Gy (I) & & 162.7 & 164.9 & 0.36 \\
\hline & & & 100 Gy (Pd) & $\mathrm{RV}_{100}>1.3 \mathrm{ml}(\%)$ & 57.1 & 0 & NS \\
\hline & & & 160 Gy (I) & & 16.7 & 27.6 & NS \\
\hline \multirow[t]{6}{*}{ Jarusevicius et al. [7] } & \multirow[t]{6}{*}{2012} & \multirow[t]{6}{*}{230} & \multirow[t]{6}{*}{160 Gy } & $P V_{100}(\%)$ & 95.5 & 94.9 & 0.21 \\
\hline & & & & $\mathrm{PV}_{150}(\%)$ & 65.3 & 53.2 & $<0.001$ \\
\hline & & & & $\mathrm{PD}_{90}(\mathrm{~Gy})$ & 184.7 & 177.9 & 0.002 \\
\hline & & & & $\mathrm{UD}_{30}(\mathrm{~Gy})$ & 218.6 & 197.4 & 0.001 \\
\hline & & & & $\mathrm{RV}_{100}\left(\mathrm{~cm}^{3}\right)$ & 0.6 & 0.3 & $<0.001$ \\
\hline & & & & HI (\%) & 31.8 & 44.0 & $<0.001$ \\
\hline \multirow[t]{5}{*}{ Ishiyama et al. [8] } & \multirow[t]{5}{*}{2014} & \multirow[t]{5}{*}{140} & \multirow[t]{5}{*}{145 Gy } & $\mathrm{PV}_{100}(\%)$ & 95.7 & 96.6 & NS \\
\hline & & & & $\mathrm{PV}_{150}(\%)$ & 62.1 & 60.4 & NS \\
\hline & & & & $\mathrm{PD}_{90}(\mathrm{~Gy})$ & 170.7 & 174.4 & NS \\
\hline & & & & $\mathrm{UD}_{30}(\mathrm{~Gy})$ & 206.8 & 203.2 & NS \\
\hline & & & & $\mathrm{RV}_{100}\left(\mathrm{~cm}^{3}\right)$ & 0.51 & 0.47 & NS \\
\hline \multirow[t]{5}{*}{ Katayama et al. [10] } & \multirow[t]{5}{*}{2016} & \multirow[t]{5}{*}{64} & \multirow[t]{5}{*}{$144 \mathrm{~Gy}$} & $\mathrm{PV}_{100}(\%)$ & 97 & 98.2 & 0.29 \\
\hline & & & & $\mathrm{PV}_{150}(\%)$ & 68.8 & 69.2 & 0.88 \\
\hline & & & & $\mathrm{PD}_{90}(\mathrm{~Gy})$ & 178.1 & 180.7 & 0.29 \\
\hline & & & & $\mathrm{UD}_{90}(\mathrm{~Gy})$ & 154.6 & 165.4 & 0.056 \\
\hline & & & & $\mathrm{RV}_{100}\left(\mathrm{~cm}^{3}\right)$ & 1.00 & 0.97 & 0.78 \\
\hline \multirow[t]{9}{*}{ Hirose et al. [11] } & \multirow[t]{9}{*}{2017} & \multirow[t]{4}{*}{24} & \multirow[t]{4}{*}{160 Gy } & $\mathrm{PD}_{90}(\mathrm{~Gy})$ & 190.3 & 190.1 & 0.98 \\
\hline & & & & HI (\%) & 33.6 & 41.3 & 0.19 \\
\hline & & & & $\mathrm{UD}_{30}(\mathrm{~Gy})$ & 248.9 & 219.9 & 0.16 \\
\hline & & & & $\mathrm{RV}_{100}\left(\mathrm{~cm}^{3}\right)$ & 0.14 & 0.23 & 0.12 \\
\hline & & \multirow[t]{5}{*}{38} & \multirow[t]{5}{*}{$110 \mathrm{~Gy}+\mathrm{EBRT}$} & $\mathrm{PV}_{150}(\%)$ & 80.2 & 62.8 & 0.001 \\
\hline & & & & $\mathrm{PD}_{90}(\mathrm{~Gy})$ & 148.3 & 134.5 & 0.004 \\
\hline & & & & HI (\%) & 18.7 & 35.7 & $<0.001$ \\
\hline & & & & $\mathrm{UD}_{30}(\mathrm{~Gy})$ & 195.1 & 165.2 & $<0.003$ \\
\hline & & & & $\mathrm{RV}_{100}\left(\mathrm{~cm}^{3}\right)$ & 0.29 & 0.31 & 0.31 \\
\hline \multirow[t]{5}{*}{ Inada et al. [12] } & \multirow[t]{5}{*}{2017} & \multirow[t]{5}{*}{74} & \multirow[t]{5}{*}{144 Gy or 110 Gy } & $\mathrm{PV}_{100}(\%)$ & 95.2 & 96.9 & 0.02 \\
\hline & & & & $\mathrm{PV}_{150}(\%)$ & 64.5 & 57.1 & 0.005 \\
\hline & & & & $\mathrm{PD}_{90}(\%)$ & 115.5 & 119.8 & 0.10 \\
\hline & & & & $\mathrm{UD}_{10}(\%)$ & 145.5 & 141.2 & 0.23 \\
\hline & & & & $\mathrm{RD}_{2 \mathrm{cc}}(\%)$ & 64.1 & 61.0 & 0.23 \\
\hline \multirow[t]{4}{*}{ Kaneda et al. [13] } & 2018 & 76 & $110 \mathrm{~Gy}+\mathrm{EBRT}$ & $\mathrm{PV}_{100}(\%)$ & 98.7 & 98.0 & 0.06 \\
\hline & & & & $\mathrm{PV}_{150}(\%)$ & 66.7 & 51.7 & $<0.001$ \\
\hline & & & & $\mathrm{PD}_{90}(\%)$ & 127.2 & 118.8 & $<0.01$ \\
\hline & & & & $\mathrm{RV}_{100}\left(\mathrm{~cm}^{3}\right)$ & 0.61 & 0.44 & 0.03 \\
\hline
\end{tabular}

$V_{100}$ - the percentage of the volume receiving $100 \%$ of the prescribed dose, $V_{150}$ - the percentage of the volume receiving $150 \%$ of the prescribed dose, $D_{90}$ - the minimum dose received by $90 \%$ of the volume, $D_{30}$ - the minimum dose received by $30 \%$ of the volume, $D_{10}$ - the minimum dose received by $10 \%$ of the volume, $D_{2 c c}$ - the minimum dose received by $2 c c$ of the volume, $H I$ - homogeneity index, $L S$-loose seed, IBCL - intraoperatively built custom-linked 
in $\mathrm{D}_{90}$ at 1 month. This may be because LS can change position according to edema of the prostate after seed implantation, and return to the intended position after resolution of the edema; whereas with IBCL seeds, the seeds are less able to move even if edema is present. In their comparison between IBCL seeds and LS, Katayama et al. performed sector analysis and reported improved dose distribution in the anterior base in the IBCL group [10]. Although our method of segmentation is different to theirs, there was no significant difference in the present study between the two groups in terms of $D_{90}$ and $V_{100}$ of AIQ at 24 hours or at 1 month.

The prevalence of GU adverse events at 3 months after implantation was significantly lower in the IBCL group than in the LS group. Furthermore, in the comparison using a cut-off value of $\mathrm{UD}_{150}$, the incidence of $\mathrm{GU}$ adverse events was significantly lower in patients with lower $\mathrm{UD}_{150}$. These results suggest that high urethral dose is associated with the occurrence of GU adverse events and that fewer GU adverse events occur in the IBCL group because the dose to the urethra was lower in this group. In their studies regarding GU adverse events after brachytherapy, Ishiyama et al. and Katayama et al. found no significant difference in the prevalence of adverse events between the two groups $[8,10]$. These previous studies evaluated only the presence or absence of adverse events, whereas the present study examined the frequency of adverse events according to the length of follow-up period, which we consider to be a more detailed analysis and the first to show a statistical advantage of IBCL seeds over LS in terms of GU adverse effects. Even though the optimal prescription dose in LDR brachytherapy is controversial, numerous studies have reported a correlation of $\mathrm{PD}_{90}$ and $\mathrm{PV}_{100}$ with prognosis $[26,27,28,29,30]$. As mentioned above, the present study found no significant difference in $\mathrm{PD}_{90}$ and $\mathrm{PV}_{100}$ between the IBCL and LS groups. Thus, these results suggest that IBCL seeds can reduce urethral dose without lowering $\mathrm{PD}_{90}$ and $\mathrm{PV}_{100}$. Moreover, the use of IBCL seeds may enable the prescription dose to increase without increasing GU adverse events and reduce biochemical recurrence of prostate cancer. These results suggest that IBCL seeds are especially recommended for small prostates. When the prostate is small, there is a limited space within the prostate, in which seeds can be inserted, and reducing the urethral dose is often difficult. Other situations where IBCL seeds may be recommended include combination therapy of brachytherapy and external beam radiation therapy, which also requires reduction of urethral dose.

This study had several limitations. First, it was limited by its retrospective design and single-center setting, a relatively short follow-up period, and a relatively low number of patients. The median follow-up time of 4.2 years in the LS group is considered short for assessing the prognosis of localized prostate cancer. However, no biological recurrence was observed during this follow-up period, and the therapeutic results of both groups may be considered acceptable. Second, CT images were used for dose evaluation. It is well-known that the seeds cause artifacts on CT that make it difficult to contour the mar- gin of the prostate, and that contouring of the prostate varies greatly between practitioners $[31,32,33]$. To eliminate these effects, we used CT-MR fusion images for contouring. Third, the brachytherapy methods vary greatly among facilities, such as prescription doses, dose limitations for organ at risk, seed insertion techniques, and evaluation periods. Therefore, attention should be given when applying the results of this study to other facilities.

\section{Conclusions}

In this retrospective single institutional study, as compared with the LS group, the IBCL group showed a decrease in the SD of the dosimetric parameters, which were statistically significant with respect to change in the variables between 24 hours and 1 month $(F$-test). The use of IBCL seeds significantly decreased $\mathrm{PV}_{150}, \mathrm{UV}_{150}$, and $\mathrm{UD}_{30}$, and significantly improved $\mathrm{HI}$ without lowering $\mathrm{PD}_{90}$ and $\mathrm{PD}_{100}$. The prevalence of $\mathrm{GU}$ adverse events at 3 months was significantly lower in the IBCL group than in the LS group.

\section{Disclosure}

The authors report no conflict of interest.

\section{References}

1. Attard G, Parker C, Eeles RA et al. Prostate cancer. Lancet 2016; 387: 70-82.

2. Waterman FM, Dicker AP. Probability of late rectal morbidity in 125I prostate brachytherapy. Int J Radiat Oncol Biol Phys 2003; 55: 342-353.

3. Dinkla AM, Pieters BR, Koedooder K et al. Prostate volume and implant configuration during 48 hours of temporary prostate brachytherapy: limited effect of oedema. Radiat Oncol 2014; 9: 272.

4. Spadinger I, Chu J, Afsari Golshan M et al. Regional dose metrics as predictors of biochemical failure and local recurrence after low-dose-rate prostate brachytherapy. Brachytherapy 2015; 14: 350-358.

5. Zauls AJ, Ashenafi MS, Onicescu G et al. Comparison of intraoperatively built custom linked seeds versus loose seed gun applicator technique using real-time intraoperative planning for permanent prostate brachytherapy. Int J Radiat Oncol Biol Phys 2011; 81: 1010-1016.

6. Saito S, Ito K, Yorozu A et al. Nationwide Japanese Prostate Cancer Outcome Study of Permanent Iodine-125 Seed Implantation (J-POPS). Int J Clin Oncol 2015; 20: 375-385.

7. Jarusevicius L, Inciura A, Juozaityte E et al. Comparison of implant quality between loose and intra-operatively linked iodine-125 seeds in prostate cancer brachytherapy. J Radiat Res 2012; 53: 439-446.

8. Ishiyama H, Satoh T, Kawakami S et al. A prospective quasirandomized comparison of intraoperatively built customlinked seeds versus loose seeds for prostate brachytherapy. Int J Radiat Oncol Biol Phys 2014; 90: 134-139.

9. Ishiyama H, Sekiguchi A, Satoh $\mathrm{T}$ et al. Dosimetry of permanent interstitial prostate brachytherapy for an interoperative procedure, using $\mathrm{O}$-arm based CT and TRUS. J Contemp Brachytherapy 2016; 8: 7-16.

10. Katayama N, Takemoto M, Takamoto A et al. Comparison of implant quality between intraoperatively built custom-linked seeds and loose seeds in permanent prostate brachytherapy using sector analysis. J Radiat Res 2016; 57: 393-399. 
11. Hirose K, Aoki M, Sato M et al. Analysis of the relationship between prescribed dose and dosimetric advantage of real-time intraoperatively built custom-linked seeds in iodine-125 prostate brachytherapy. Radiat Oncol 2017; 12: 192.

12. Inada $M$, Yokokawa M, Minami $T$ et al. Dosimetry advantages of intraoperatively built custom-linked seeds compared with loose seeds in permanent prostate brachytherapy. J Contemp Brachytherapy 2017; 9: 410-417.

13. Kaneda T, Ohashi T, Sakayori M et al. Plan reproducibility of intraoperatively custom-built linked seeds compared to loose seeds for prostate brachytherapy. J Contemp Brachytherapy 2018; 10: 291-296.

14. Guinot JL, Ricos JV, Tortajada MI et al. Comparison of permanent (125)I seeds implants with two different techniques in 500 cases of prostate cancer. J Contemp Brachytherapy 2015; 7: 258-264.

15. Roach M, 3rd, Hanks G, Thames H, Jr. et al. Defining biochemical failure following radiotherapy with or without hormonal therapy in men with clinically localized prostate cancer: recommendations of the RTOG-ASTRO Phoenix Consensus Conference. Int J Radiat Oncol Biol Phys 2006; 65: 965-974.

16. Zaorsky NG, Davis BJ, Nguyen PL et al. The evolution of brachytherapy for prostate cancer. Nat Rev Urol 2017; 14: 415-439.

17. Yu Y, Anderson LL, Li Z et al. Permanent prostate seed implant brachytherapy: report of the American Association of Physicists in Medicine Task Group No. 64. Med Phys 1999; 26: 2054-2076

18. Snyder KM, Stock RG, Hong SM et al. Defining the risk of developing grade 2 proctitis following 125I prostate brachytherapy using a rectal dose-volume histogram analysis. Int J Radiat Oncol Biol Phys 2001; 50: 335-341.

19. Nag S, Bice W, DeWyngaert K et al. The American Brachytherapy Society recommendations for permanent prostate brachytherapy postimplant dosimetric analysis. Int J Radiat Oncol Biol Phys 2000; 46: 221-230.

20. Papagikos MA, Deguzman AF, Rossi PJ et al. Dosimetric quantifiers for low-dose-rate prostate brachytherapy: is $\mathrm{V}(100)$ superior to D(90)? Brachytherapy 2005; 4: 252-258.

21. Serrano NA, Anscher MS. Favorable vs unfavorable intermediate-risk prostate cancer: a review of the new classification system and its impact on treatment recommendations. Oncology (Williston Park) 2016; 30: 229-236.

22. Okazaki E, Kuratsukuri K, Ishii K et al. Correlations of post-implant regional dosimetric parameters at 24 hours and one month, with clinical results of low-dose-rate brachytherapy for localized prostate cancer. I Contemp Brachytherapy 2017; 9: 499-507.

23. Morris WJ, Keyes M, Spadinger I et al. Population-based 10-year oncologic outcomes after low-dose-rate brachytherapy for low-risk and intermediate-risk prostate cancer. Cancer 2013; 119: 1537-1546.

24. Saw CB, Suntharalingam N. Quantitative assessment of interstitial implants. Int J Radiat Oncol Biol Phys 1991; 20: 135-139.

25. Nag S, Beyer D, Friedland J et al. American Brachytherapy Society (ABS) recommendations for transperineal permanent brachytherapy of prostate cancer. Int J Radiat Oncol Biol Phys 1999; 44: 789-799.

26. Stock RG, Stone NN, Tabert A et al. A dose-response study for I-125 prostate implants. Int J Radiat Oncol Biol Phys 1998; 41: 101-108.

27. Sidhu S, Morris WJ, Spadinger I et al. Prostate brachytherapy postimplant dosimetry: a comparison of prostate quadrants. Int J Radiat Oncol Biol Phys 2002; 52: 544-552.
28. Nath R, Bice WS, Butler WM et al. AAPM recommendations on dose prescription and reporting methods for permanent interstitial brachytherapy for prostate cancer: report of Task Group 137. Med Phys 2009; 36: 5310-5322.

29. Nasser NJ, Wang Y, Borg J et al. Sector analysis of dosimetry of prostate cancer patients treated with low-dose-rate brachytherapy. Brachytherapy 2014; 13: 369-374.

30. Kirschner AN, Sathiaseelan V, Zhang Y et al. Multisector dosimetry in the immediate post-implant period: significant under dosage of the prostate base. J Contemp Brachytherapy 2014; 6: 33-39.

31. Polo A, Cattani F, Vavassori A et al. MR and CT image fusion for postimplant analysis in permanent prostate seed implants. Int J Radiat Oncol Biol Phys 2004; 60: 1572-1579.

32. Tanaka O, Hayashi S, Matsuo M et al. Comparison of MRIbased and CT/MRI fusion-based postimplant dosimetric analysis of prostate brachytherapy. Int J Radiat Oncol Biol Phys 2006; 66: 597-602.

33. Maletz KL, Ennis RD, Ostenson J et al. Comparison of CT and MR-CT fusion for prostate post-implant dosimetry. Int J Radiat Oncol Biol Phys 2012; 82: 1912-1917. 